\title{
A internacionalização para as Ciências Humanas no Brasil: um olhar Brasil - Espanha'
}

\author{
Richard Davis \\ Université de Lille 3 \\ Rafael Sumozas \\ Universidad de Castilla-La Mancha \\ Flavia Melville Paiva \\ Universidade Federal de Mato Grosso do Sul
}

\section{Resumo}

Este artigo analisa a internacionalização das Ciências Humanas, subárea Educação, especificamente, a educação superior. Para tanto, analisa os dados dos dois maiores órgãos federais de fomento à pesquisa, comparando financiamento e resultados reservados às diversas áreas do conhecimento, com o objetivo de suscitar um questionamento sobre o emprego dos investimentos das políticas públicas de incentivo à internacionalização da educação superior; e analisa o relato da experiência de dois agentes de Educação em mobilidade por financiamento europeu (Projeto IBrasil do Programa Erasmus Mundus). Assim, chega-se à conclusão de que programas como 12 este atendem às necessidades da subárea e propiciam o crescimento científico, profissional e pessoal, além de refletir o papel da sociedade frente ao mundo globalizado. Palavras-chave: Internacionalização. Políticas públicas. Educação.

\section{Internationalization for Human Sciences in Brazil: a Brazil - Spain analysis}

\section{Abstract}

This article presents an analysis of the internationalization of Human Sciences, subarea Education, specifically the higher education. It analyzes the data from the two largest federal fostering research agencies, comparing financing and results reserved for various areas of knowledge, in order to raise a question on the use of investments of public policies to encourage the internationalization of higher education; and analyzes the experience of two Education agents that had their internationalized mobilities with European funding (IBrasil Project - Erasmus Mundus Programme). Therefore, we have concluded that programs like this answer the needs and provide the scientific, professional and personal growth of the subarea, as well as a reflection of the role of society facing the globalized world.

Keywords: Internationalization. Public policies. Education. 


\section{Internacionalización de Ciencias Humanas en Brasil: una mirada Brasil - España}

\section{Resumen}

En este artículo se presenta un análisis de la internacionalización de las Ciencias Humanas, subárea de Educación, específicamente la educación superior. Se analizan los datos de las dos mayores agencias federales que fomentan la investigación, que comparan la financiación y los resultados reservados para diversas áreas de conocimiento, con el fin de plantear una pregunta sobre el uso de las inversiones de las políticas públicas para fomentar la internacionalización de la educación superior; y analiza el relato de la experiencia de dos agentes de Educación que tuvieron en movilidad por el Proyecto Ibrasil - Programa Erasmus Mundus. resulta que programas como este satisfacen las necesidades de la subárea y proporcionan el crecimiento científico, profesional y personal, así como la reflexión sobre el papel de la sociedad frente al mundo globalizado. Palabras-clave: Internacionalización. Políticas públicas. Educación.

\section{Introdução}

O presente artigo tem o objetivo de suscitar uma análise quanto à internacionalização do saber da área de Ciências Humanas, subárea de Educação, especificamente a Educação Superior, tendo, como procedimento metodológico, a análise dos dados disponibilizados pela Coordenação de Aperfeiçoamento de Pessoal de Nível Superior (Capes) e pelo Conselho Nacional de Desenvolvimento Científico e Tecnológico (CNPq), duas agências federais de fomento à pesquisa relacionadas, respectivamente, ao Ministério da Educação e ao Ministério de Ciência, Tecnologia e Inovação brasileiros, assim como a análise do discurso de dois agentes da Educação que buscaram financiamento europeu para suas mobilidades no ano de 2015 , sendo uma acadêmica brasileira e um professor espanhol.

Os dados da Capes referem-se ao Sistema de Avaliação da PósGraduação (SAPG) que vem sendo usado, desde 1976, para avaliar os programas de pós-graduação brasileiros, conferindo-thes nota de 1 a 5 para critérios nacionais de excelência (sendo a nota mínima para manutenção do programa a 3) e notas 6 e 7 quando esses programas apresentam critérios de inserção internacional de suas pesquisas. 
Conselho Nacional de Desenvolvimento Científico e Tecnológico (CNPq) teve os dados referentes ao número de bolsas de mobilidade internacionais no período de 2001 a 2014 , apresentando o crescimento ou retração dessa oferta nas diferentes áreas do conhecimento, atentando para a comparação destas com a área de Ciências Humanas e, mais especificamente, a Educação com sua subárea.

Após essa análise, apresentaram-se dados coletados em entrevista com dois agentes da Educação, contendo semelhanças, diferenças e complementaridades em seus discursos sobre a internacionalização do saber na Educação.

Inicialmente, fez-se necessário estabelecer o que a pesquisa entende como internacionalização da Educação.

A definição, cunhada para esse termo, encontrou em Van der Wende (1997) a motivação inicial, afirmando que o termo internacionalização seria conceituado como

[...] qualquer esforço sistemático, sustentado, e que tem por objetivo tornar o ensino superior (mais) responsivo às demandas e desafios relacionados à globalização das sociedades, da economia e do mercado de trabalho (VAN DER WENDE, 1997, p. 30).

Para a tal definição, foi proposta a complementação dada por Miura (2006, p. 30) que apontou que a afirmação de Van de Wende apresentava "[...] respostas ao ambiente externo, especificamente à globalização [...]" e propôs a conscientização da necessidade de contextualizar a internacionalização "[...] especificamente para o setor educacional".

Para finalizar, tem-se o desafio proposto por Knight (2008, p. 1) ao estabelecer que a "[...] internacionalização está mudando o mundo da educação superior, e a globalização está mudando a internacionalização", chegando à definição proposta por de De Wit (2015) de ser a internacionalização:

O processo intencional de integrar uma dimensão internacional, intercultural ou global à finalidade, funções e oferta de ensino pós-secundário, com o interesse de melhorar a qualidade do ensino e da pesquisa para todos os alunos e funcionários, e trazer uma contribuição significativa para a sociedade (DE WIT, 2015, p. 24, tradução livre). 
Nessa perspectiva, sugere-se o recorte de analisar a internacionalização da Educação Superior, mediante a mobilidade internacional realizada pelos seus diferentes agentes, de acadêmicos a discentes de pós-graduação, docentes, pós-doutores, pesquisadores.

Nesse momento de mudanças, via esforço sistemático, visando ao crescimento pela globalização, a internacionalização da educação superior no Brasil tem sido incentivada com apoio financeiro expressivo de agências de fomento federais, estaduais e municipais, bem como a de iniciativa privada, inclusive não nacionais.

O cenário mundial, está pautado pelo o que foi proposto pela Declaração Mundial sobre Educação Superior no Século XXI: Visão, realizada em Paris, em 1998, de que, para assegurar um desenvolvimento endógeno genuíno e sustentável, há a necessidade de uma educação superior e com instituições de pesquisa adequadas que "[...] formem a massa crítica de pessoal qualificadas e cultas [...]", com o objetivo de reduzir a disparidade que separa "[...] os países pobres e em desenvolvimento dos países desenvolvidos" (UNESCO, 1998).

Tal documento salientou que, para alcançar qualidade na educação superior, é preciso apresentar características internacionais, como intercâmbio de conhecimentos, criação de redes interativas, mobilidade docente e discente e projetos de pesquisa internacional (BRASIL, 1996); no artigo 15, estabelece como importante compartilhar conhecimentos teóricos e práticos entre países e continentes, propondo o princípio da "solidariedade e de uma autêntica parceria entre instituições de educação superior em todo o mundo".

Já em 2009, a Conferência Mundial sobre Ensino Superior, intitulada "As Novas Dinâmicas do Ensino Superior e Pesquisas para a Mudança e ao Desenvolvimento Social", também promovida pela Organização das Noções Unidas para a educação, a ciência e a cultura (Unesco), dedica um capítulo inteiro à internacionalização como sendo a pesquisa e o ensino superior possíveis de contribuir para o desenvolvimento sustentável e para o progresso; nesse capítulo, estabeleceu pontos importantes a serem respeitados quanto à cooperação internacional, responsabilidade social e desenvolvimento mundial, estabelecimento de redes universitárias e parcerias de pesquisa com preocupação pela igualdade de acesso, inserção social, entre outros. 
No Brasil, por exemplo, foram estabelecidas as finalidades da educação superior brasileira pela Lei de Diretrizes e Bases da Educação Nacional (BRASIL, 1996), de estimular a criação e o desenvolvimento do espírito científico e do pensamento reflexivo, formar especialistas em diversas áreas do conhecimento com a aptidão a entrar no mercado de trabalho e participar no desenvolvimento da sociedade brasileira que, mesmo de cunho nacionalista, ao incentivar o ensino, a pesquisa e a investigação científica, com a difusão do saber científico e tecnológico, abriu a possibilidade de buscar, em outras nações, apoio para a concretização de seus objetivos.

Como consequência dessa busca pela excelência na educação, pode-se encontrar a evolução nos Planos Nacionais de Pós-graduação (PNPG), desenvolvidos pela política nacional de Ciência e Tecnologia, que, já na década de 1970, sabia da necessidade de motivação à capacitação de profissionais brasileiros no exterior, uma vez que o Brasil ainda não tinha programas de pós-graduação (MOROSINI, 201 1, p. 98).

Sá Barreto (2006, p. 157) analisou as principais propostas e metas dos três primeiros PNPGs, afirmando que o "[...] desempenho da pós-graduação sempre contou com a permanente participação da comunidade academia nacional e foi integrado por ações específicas com a comunidade científica internacional".

Como ferramenta de apoio ao PNPG e, para avaliar os programas de pós-graduação brasileiros, o SAPG da Capes, foi desenvolvido em 1976, sendo um sistema de acompanhamento anual e avaliação trienal que, a partir de 2015, passará a ser quadrienal.

Inicialmente, serão apresentadas como, nos últimos 14 anos, as duas maiores agências de fomento em nível federal à pesquisa, ou seja, Capes e CNPq, vem trabalhando internacionalização da educação superior e a mobilidade internacional para diferentes áreas do conhecimento através do financiamento de bolsas de estudo e avaliação da inserção internacional dos programas de pós-graduação.

Os dados disponibilizados em transparência por suas páginas na Internet apontam, por si só, como as áreas de conhecimento têm reagido de formas diferentes ao fenômeno da internacionalização do saber. Assim, é possível perceber que o incentivo das políticas públicas de internacionalização 
da Educação, em comparação a outras áreas de saber, não tem gerado unicidade.

Na da realidade apresentada, verificou-se a necessidade de dois representantes da área de Educação buscarem sua internacionalização acadêmica, utilizando financiamento não nacional.

Nesse cenário, a segunda proposta é a análise do relato desses dois agentes de Educação, que realizaram mobilidade cruzada entre duas universidades participantes do projeto lbrasil, Erasmus Mundus, sendo uma universidade espanhola e outra brasileira, para procurar entender suas motivações e necessidades, apontando congruências e divergências e complementaridades em seus discursos com base nas políticas públicas de internacionalização da educação brasileira.

\section{O Sistema de Avaliação da Pós-Graduação da Capes (SAPG) - dados comparativos}

A proposta de estudar as políticas educacionais consiste em procurar entender melhor como elas ocorrem em nível local e mundial. A internacionalização do saber apontada pelas avaliações do SAPG - Capes apresenta que alguns programas de pós-graduação não alcançaram a mesma representatividade de outras áreas de conhecimento, quando avaliados em sua inserção internacional.

Essa representatividade é analisada por França e Bonamino (20) 14, p. 126) que inicia sua pesquisa sobre a "Avaliação e gestão da excelência na pós-graduação em educação [...]" apresentando que a área de Educação "[...] é uma das que concentra o maior número de programas de pós-graduação stricto sensu, entre as 48 áreas de conhecimento [...]", no entanto, percebe-se, ao analisar as últimas três avaliações trienais realizadas pela Capes (anos de 2004-2006, 2007-2009 e 2010-201 2), que a representatividade dessa área de conhecimento em programas avaliados como 6 ou 7 , ou seja, com critérios de inserção internacional, não é tão presente quanto em outras áreas.

A autora aponta que, na última avaliação (2013), ocorreu uma "grande concentração na nota $4(4$ \%), seguida pela nota $3(38 \%)$ e pela nota 
$5(14 \%)^{\prime \prime}$ e, ao analisar os programas com notas 6 e 7 , do total de cursos, $5 \%$ na nota 6 e $2 \%$ na nota 7 .

A Capes está em franca valorização da internacionalização do saber e das pesquisas, e com o desafio de aperfeiçoar os programas de pós-graduação; as diferentes áreas de conhecimento têm-se reunido e traçado metas a serem alcançadas nos próximos anos, que poderão ser avaliadas já no próximo quadriênio.

Essa diversidade entre áreas de conhecimento e, principalmente, a diferença de resposta frente ao fenômeno ora estudado gera a necessidade de se entender como as políticas públicas de educação têm apoiado as áreas de conhecimento, questionando se esse apoio tem sido equânime em oferta e procura.

Para łanto, inicia-se com a análise dos dados disponibilizados, em 2014 , pela Capes em sua última avaliação pelo Sistema de Avaliação da PósGraduação (SAPG) referente ao triênio 2010-2012.

A tabela abaixo apresenta a avaliação disponibilizada, em 2013, para as nove grandes áreas de avaliação:

Tabela 1

Grandes áreas avaliadas em seus critérios de inserção internacional (Capes)

\begin{tabular}{|l|c|c|c|}
\hline $\begin{array}{c}\text { Avaliação Capes triênio } \\
2010-2013\end{array}$ & \multicolumn{2}{|c|}{ Conceito } & $\begin{array}{c}\text { Total de Programas (avaliados } \\
\text { de 3 a 7) }\end{array}$ \\
\cline { 1 - 2 } Área de conhecimento & 6 & 7 & 365 \\
\hline Ciências Agrárias & 31 & 15 & 281 \\
\hline Ciências Biológicas & 45 & 19 & 537 \\
\hline Ciências da Saúde & 49 & 24 & 290 \\
\hline Ciências Exatas e da Terra & 250 & 33 & 471 \\
\hline Ciências Humanas & 32 & 21 & 413 \\
\hline Ciências Sociais Aplicadas & 31 & 7 & 362 \\
\hline Engenharias & 274 & 20 & 178 \\
\hline Linguística, Letras e Artes & 12 & 5 & 440 \\
\hline Multidisciplinar & 18 & 1 & \\
\hline
\end{tabular}

Fonte | SAPG/Capes (2010-2013) 
Em uma análise da quantidade de programas existentes em cada área de conhecimento elencada pelo SAPG e o percentual de programas que alcançaram as notas 6 e 7 , é possível verificar que, por exemplo, áreas como Engenharias e Tecnologias, Ciências Biológicas e da Saúde, Ciências da Terra têm apresentado uma efetiva participação no rol dos programas com inserção internacional, se comparados com as Ciências Humanas e Sociais.

Inserida nessa grande área Ciências Humanas, esta desproporcionalidade entre quantidade de programas existentes e quantidade de programas avaliados em 6 e 7 também foi possível de verificar, sendo que a Educação foi a subárea de conhecimento das Ciências Humanas com menor percentual de programas em 6 ou 7 , mas menor percentual em relação à totalidade dos programas avaliados.

\section{Tabela 2}

Subárea das Ciências Humanas avaliadas em seus critérios de inserção internacional (Capes)

\begin{tabular}{|c|c|c|c|}
\hline Avaliação Capes triênio $2010-2013$ & \multicolumn{2}{|c|}{ Conceito } & \multirow{2}{*}{$\begin{array}{l}\text { Total de Programas (ava- } \\
\text { liados de } 3 \text { a } 7 \text { ) }\end{array}$} \\
\hline Subáreas & 6 & 7 & \\
\hline Antropologia/ Arqueologia & 2 & 3 & 26 \\
\hline $\begin{array}{l}\text { Ciências Políticas e Relações } \\
\text { Internacionais }\end{array}$ & 4 & 2 & 32 \\
\hline Educação & 6 & 3 & 121 \\
\hline $\begin{array}{l}\text { Filosofia/Teologia: subcomissão } \\
\text { Filosofia }\end{array}$ & 4 & 2 & 42 \\
\hline $\begin{array}{l}\text { Filosofia/Teologia: subcomissão } \\
\text { Teologia }\end{array}$ & 3 & 0 & 17 \\
\hline Geografia & 3 & 3 & 49 \\
\hline História & 4 & 2 & 63 \\
\hline Psicologia & 3 & 3 & 69 \\
\hline Sociologia & 3 & 3 & 52 \\
\hline
\end{tabular}

Fonte | SAPG/Capes (2010-2013) 


\section{O CNPq e a internacionalização do saber nas áreas de subáreas de conhecimento}

Paralela a essa análise, têm-se dados disponibilizados pelo CNPq, em que é possível verificar como as bolsas de estudo no exterior vêm sendo financiadas nos últimos anos e nas diversas áreas de conhecimento.

Tabela 3

Investimento CNPq em bolsas no exterior

\begin{tabular}{|c|c|c|c|c|c|c|c|c|c|}
\hline & 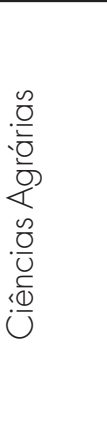 & 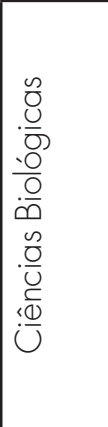 & 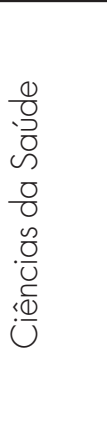 & 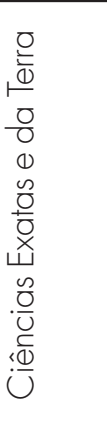 & 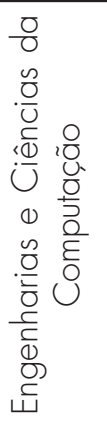 & 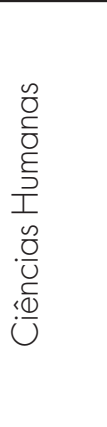 & 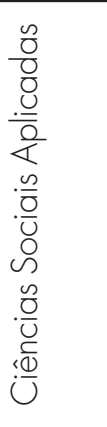 & 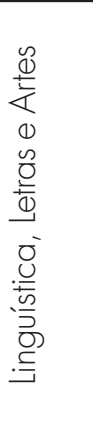 & $\begin{array}{l}\overline{\overline{0}} \\
\underline{0}\end{array}$ \\
\hline 2000 & 2388 & 2975 & 926 & 5929 & 7246 & 2250 & 1815 & 878 & 24.407 \\
\hline 2010 & 3310 & 3329 & 2459 & 4365 & 5981 & 2622 & 1562 & 939 & 24.567 \\
\hline$\%$ crescimento & 39 & 12 & 166 & -27 & $-17,5$ & 16,5 & -14 & 7 & 0,65 \\
\hline
\end{tabular}

Fonte | CNPq (2000-2010)

Verifica-se que, de 2000 a 2010 , ocorreu um crescimento de 16,5\% no investimento em Ciências Humanas, o que poderia ser um dado positivo para a área, mas não se pode deixar de compará-lo ao crescimento ocorrido em outras áreas, como, por exemplo, 166\% para Ciências da Saúde. 
Tabela 4

Bolsas concedidas em 2014 e o impacto do Ciência sem Fronteiras

\begin{tabular}{|c|c|c|c|c|c|c|c|c|c|}
\hline & 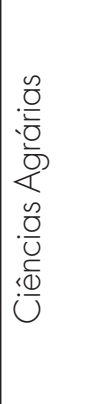 & 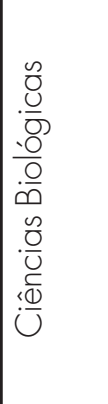 & 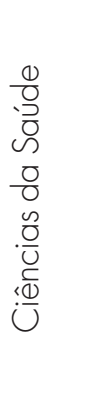 & 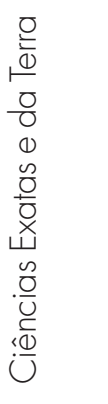 & 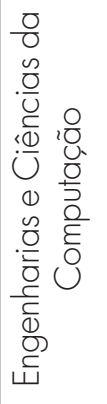 & 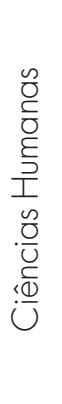 & 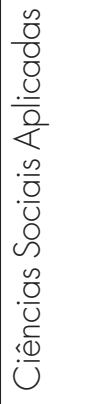 & 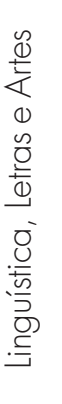 & $\begin{array}{l}\overline{\underline{0}} \\
\underline{0}\end{array}$ \\
\hline 2014 & 501 & 1090 & 1156 & 1746 & 4896 & 71 & 1098 & 63 & 10621 \\
\hline $\begin{array}{l}\text { Impacto graduação } \\
\text { sanduiche (CsF) em } \\
2014\end{array}$ & 358 & 711 & 999 & 1335 & 4659 & 6 & 1038 & 48 & 9154 \\
\hline
\end{tabular}

Fonte $\mathrm{CNPq}$ (2014)

A graduação sanduíche vem sendo incentivada especialmente, desde 2011 , com o lançamento do programa Ciência sem Fronteiras pelo governo federal (BRASIL, 2011) e as primeiras chamadas para candidatura denominavam áreas prioritárias possibilitando que todas as áreas de conhecimento participassem do certame, mas, atualmente, as denomina áreas contempladas, excluindo cursos das Ciências Humanas, por exemplo, incluindo Ciências da Saúde, Biológicas, Exatas e da Terra, Agrárias e Engenharias e Ciências da Computação.

\section{Tabela 5}

Publicação internacional 2000-2010

\begin{tabular}{|c|c|c|c|c|c|c|c|c|c|}
\hline $\begin{array}{l}\text { Publicação } \\
\text { internacional }\end{array}$ & 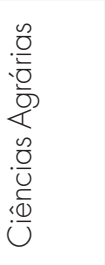 & 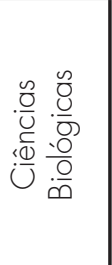 & $\begin{array}{l}0 \\
0 \\
0 \\
0 \\
0 \\
0 \\
0 \\
\frac{0}{0} \\
\frac{0}{0} \\
\frac{c}{0} \\
0\end{array}$ & 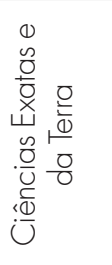 & 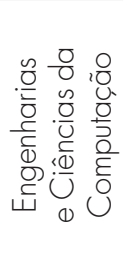 & 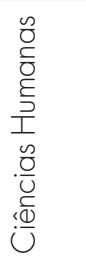 & 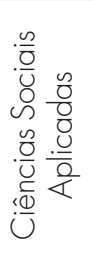 & 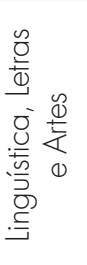 & $\begin{array}{l}\bar{D} \\
\underline{0}\end{array}$ \\
\hline Quad. 2000-2003 & 12099 & 31413 & 23899 & 39587 & 18593 & 4407 & 2440 & 1237 & 226.675 \\
\hline Quad. 2007-2010 & 39073 & 84397 & 88441 & 64777 & 39559 & 9582 & 5724 & 1649 & 338.202 \\
\hline \% Crescimento & 3332 & 2211 & 1116 & -50 & 111 & 443 & 665 & 1174 & 443 \\
\hline
\end{tabular}

Fonte | CNPq (2000-2003; 2007-2010) 
Propõe-se a análise dos dados referentes ao crescimento do número de publicações internacionais, questionando se pode ser consequência do crescimento ocorrido no investimento em determinadas áreas de conhecimento. Nesse sentido, percebe-se que as Ciências Humanas tiveram um aumento em $43 \%$ de sua produção científica internacionalizada, o que precisa, novamente, ser comparado com os 332\% das Ciências Agrárias.

Capes e CNPq, representantes do MEC e MCT respectivamente, trazem dados que induzem a questionar o interesse brasileiro em incentivar 0 desenvolvimento da Ciência e Tecnologia em nosso país em oposição à necessidade de valorização da Educação como base para a construção de um país desenvolvido.

\section{O Programa Erasmus Mundus e o Projeto IBrasil}

O programa de mobilidade e cooperação no Ensino Superior denominado Erasmus Mundus 2009-20 13 foi implementado pela Agência Executiva de Educação Audiovisual e Cultura (EACEA - Education, Audiovisual and

22 Culture Executive Agencyl, e na sua vertente 1, ação 2, tem como principais objetivos:

- Promover o ensino superior europeu.

- Incentivar o reforço e a melhoria das perspectivas de carreira dos estudantes.

- Favorecer o entendimento intercultural por meio da cooperação com outros países, em harmonia com os objetivos da política externa da União Europeia (EU), com a meta de contribuir para o desenvolvimento sustentável do Ensino Superior de países terceiros.

Nessa vertente, o Erasmus Mundus desenvolve o projeto IBRASIL, com gestão realizada sob a supervisão da Direção-Geral EuropeAid (DG Aldco).

Assim, o IBrasil é uma associação cujo nome foi formado pela junção da letra I simbolizando a inclusão e a inovação ao nome de nosso país, sendo composta por 11 instituições de ensino superior (IES) brasileiras e 9 europeias, apresentando diversidade linguística e geográfica riquíssimas, abordando não apenas as áreas de Engenharia e tecnologia, mas também a Educação e o Treinamento de professores. 
E tem como principais objetivos:

- Treinar uma nova geração de professores, engenheiros e pesquisadores altamente qualificados que estejam abertos a valores adicionais e à inovação social e tecnológica.

- Promover programas conjuntos sustentáveis e pesquisas em comum, envolvendo estudantes, corpo docente e pesquisadores brasileiros e europeus.

- Aumentar a colaboração entre as Instituições de Ensino Superior europeias e brasileiras, além de promover ferramentas que possibilitam a cooperação internacional e o reconhecimento acadêmico das mobilidades dos estudantes.

Vale salientar que, além das 20 IES, o projeto tem, também, instituições parceiras com o objetivo de majorar a possibilidade de inclusão da comunidade indígena e quilombolas, além de outras minorias sociais existentes.

Analisando as ofertas das universidades brasileiras para recepção de alunos, professores, técnicos e pesquisadores europeus, percebe-se que aproveitaram para oferecer vagas em seus cursos de tecnologias, mas também para vários cursos de licenciatura e educação a distância.

A universidade estudada, nesta pesquisa, fez tal escolha estratégica de incentivo às licenciaturas, e até o presente momento, foi possível receber 2 acadêmicos provenientes da universidade grega parceira do programa e um professor espanhol, lotado na pós-graduação e com atuação em educação a distância. Pode também enviar dois acadêmicos do curso de pedagogia de seu campus localizado no interior do estado um para uma universidade na Espanha e outra na Grécia.

Convém ressaltar que o programa seleciona os candidatos preocupados com o balanço entre as instituições envolvidas e entre os alunos, quanto ao critério de gênero.

Na perspectiva de estudar a área de Educação e sua participação na internacionalização do conhecimento, após essa apresentação dos incentivos brasileiros para a internacionalização de diversas grandes áreas do conhecimento e a existência de órgãos de fomento estrangeiros atuando em nosso território, pretende-se colocar em diálogo dois agentes de educação, uma acadêmica e um docente, a primeira, brasileira e o segundo espanhol visando analisar seus discursos quanto à percepção da internacionalização da educação. 


\section{O discurso dos dois agentes da Educação em mobilidade}

\section{Os agentes}

A acadêmica do curso de Pedagogia de um campus do interior do estado pesquisado, estava ao s 26 anos de idade cursando o sexto período na data de sua viagem.

$\bigcirc$ currículo acadêmico do professor apresenta graduação em Pedagogia e em História da Arte, mestrado em Artes Visuais e Educação, Doutorado em História da Arte todos realizados na Espanha, seu primeiro pós-doutorado realizado no México e o segundo em uma universidade federal brasileira.

Vale salientar que há consciência da diferença em titulação e experiência profissional, mas essa diferença não ocorre na escolha da área de conhecimento para desenvolvimento, ou seja, a Educação.

\section{Os questionamentos}

A proposta de análise do discurso dos atores envolvidos nesta pesquisa partiu do questionamento de pontos relacionados à suas experiências vividas desde o momento de candidatura, ou seja, verbalização de sua necessidade em buscar a internacionalização como proposta de crescimento profissional e pessoal, a escolha da universidade a propor a candidatura e a consequente seleção de informações a serem apresentadas.

É preciso investigar como as universidades origem apoiaram ou não suas propostas, com envolvimento de suas coordenações ou chefias bem como a participação das universidades destino. Nesse quesito, as universidades destino foram envolvidas somente pós-candidatura.

Para entender o momento que vivenciaram de selecionar informações, interpretando suas aspirações e expectativas frente à mobilidade para preencher a ficha de aplicação e expor seus projetos, questionaram-se as expectativas quanto ao futuro período em outro país, incluindo seus objetivos.

Para analisar dados práticos já da mobilidade, houve a necessidade de ter conhecimento dos seus planos de trabalho inicialmente propostos principalmente verificando a participação ou não de terceiros em sua elaboração. 
Com isso, pôde-se partir para o momento pós-seleção, quando o agente chega à universidade destino e questiona se houve a necessidade de adaptação ou modificação de seus planos de trabalho, apontando motivos.

Nesse momento, foi questionado como a realidade encontrada foi de semelhança ou diferença em comparação com sua instituição de origem.

Quanto às atividades realizadas, se pode participar de outras atividades além do plano de trabalho que teve o apoio de alunos, colegas e tutores.

Assim, chegou-se o momento de colher os frutos da mobilidade ao se indagar se e como a experiência vivida proporcionou impacto profissional ou pessoal e se abriram oportunidades de novas parcerias pós mobilidade de possíveis projetos, se esta futura aplicação profissional era objetivo inicial proposta na mobilidade ou se ocorreu como consequência do período disponibilizado para a nova mudança.

Tais questionamentos foram permeados pela pergunta sobre como eles, após o retorno a seus países, percebem a necessidade de internacionalização na Educação tanto no Brasil quanto na Espanha.

\section{A escolha da universidade destino}

A motivação para a escolha da universidade apresentou critérios diferentes, provavelmente, um traço marcado pela maturidade na carreira em educação. Nesse sentido, a acadêmica baseou sua escolha em dois critérios: o primeiro - a competência linguística - já que possuía algum domínio do espanhol e que sabia que Portugal seria muito mais concorrido; o segundo critério deveu-se ao fato de haver encontrado uma área de estudo na universidade espanhola que não é muito abordada em sua universidade origem, a Educação Social (ES). Já o docente, que já tinha experiência acadêmica de mobilidade internacional para outro estado brasileiro, em seu currículo, descreve como justificativa da escolha o interesse em conhecer a programa de estudos ali desenvolvido na área de Tecnologia e Educação a Distância (TEAD). Acrescenta-se, ainda, o desejo de compartilhar experiências e mostrar casos de estudos efetivados em sua universidade para compartilhar técnicas e recursos com professores e alunos, desde os que propõem modelos de docência, pesquisa e transferência sobre tecnologia e educação a distância, centrados na imagem como modelo de pesquisa, até o desenvolvimento de 
estratégias para a construção educativa a distância. Ademais, levou em consideração que a universidade brasileira conta com onze campi no interior do estado que demandam de desenvolvimento de conteúdos multimídia pela sua coordenadoria de educação a distância, fato semelhante àquele ocorrido com a universidade espanhola e seus quatro campi.

\section{As expectativas}

Em ambos os casos, a aluna na área de ES e o professor em TEAD esperavam se desenvolver profissionalmente; conhecer culturas diferentes e construir o que denominou "pontes" com outros profissionais para a construção de sua vida profissional e pessoal.

Para o professor, a consciência de que seria possível ampliar o acesso a novas formas de gestão da EAD, desde a observação direta do modelo desenvolvido na universidade brasileira especialista, nesse tipo de educação, e avaliada por um órgão de prestígio internacional por sua avaliação da qualidade da docência e pesquisa - a Capes. Os relatórios do SAPG, desde 2007, vem apontando melhorias na universidade brasileira, em especial, na

26 EAD. Assim, acreditava poder desenvolver um trabalho frutífero para adicionar ao já experimentado em sua universidade.

\section{O plano de trabalho e sua aplicabilidade}

Por força de procedimentos internos à sua universidade de origem, e à necessidade de estabelecer o plano de estudos também com a universidade que o selecionou, todo aluno brasileiro da universidade pesquisada precisa selecionar disciplinas e atividades previamente à sua viagem. Tal plano contou com a supervisão e apoio do coordenador do curso e o aval final do colegiado superior do campus, sendo levado à pró-reitoria de graduação brasileira para análise e efetivação do afastamento por mobilidade. Como a universidade espanhola proporciona ao aluno estrangeiro a possibilidade de assistir, por duas semanas, a aulas antes de consolidar o plano de estudos, a aluna pode melhor analisar as disciplinas escolhidas inicialmente e modificar sua escolha.

Quanto ao plano de trabalho para o estágio docente, este foi apresentado pelo professor em mobilidade e teve a aquiescência do coordenador da EAD brasileiro, propondo o trabalho da imagem como modelo de investigação 
educativa a distância, podendo trabalhar, diretamente, com alunos e professores do campus e fazendo gravações e entrevistas com discentes, docentes e técnicos que trabalham com imagem como forma de pensamento e método de pesquisa. O plano inicial previa a possibilidade de conhecer os onze campi do interior, tendo sido concretizada a visita a dois deles, permitindo, assim, uma amostra significativa de como são percebidos os conteúdos audiovisuais gerados pela coordenadoria em EAD que fica estabelecida na capital do estado.

\section{A realidade encontrada}

Interessante verificar que a realidade encontrada em sala de aula de graduação em um país europeu foi considerada muito semelhante àquela que a aluna estava acostumada, a grande diferença estava na estrutura para pesquisa existente, e a possibilidade de conhecer e trabalhar em laboratórios equipados.

Em EAD, a diferença não existiu, o professor visitante teve suas expectativas cumpridas por encontrar instalações, qualificação de pessoal à altura de um país continental como o Brasil, com o que ele definiu ter "grande projeção acadêmica e científica internacional'. Isso chamou a atenção para o número de professores pesquisadores, no que diz respeito à qualidade da docência e pesquisa, ao número de revistas cientificas e a descentralização da EAD para atender à demanda das várias regiões do estado, além do estímulo à realização de atividades relacionadas com a educação, pesquisa e extensão, a preservação de recursos naturais, especialmente a flora e fauna e os estudos realizados sobre o ecossistema em que o estado está inserido.

\section{A internacionalização na área de conhecimento da Educação - Brasil e Espanha}

Foi apontado pelo professor visitante que, atualmente, "[...] não se concebe o desenvolvimento de nossa docência sem a pesquisa associada e sem a necessária internacionalização da mesma [...]" e que é impossível desenvolver seu trabalho docente de forma isolada ou local. É necessário, pois, "abrir novos horizontes", o que deixa claro ao observar a abertura da 
internacionalização existente na universidade brasileira em estudo e no Brasil em geral, onde o governo federal já oferta bolsas de estudo Brasil-Europa e Europa-Brasil que é de conhecimento de professores, alunos e técnicos brasileiros.

Para a acadêmica, a internacionalização traz a possibilidade de conhecimento de novos costumes, exemplifica ao apontar como a participação de alunos em sala de aula é diferente entre os dois países, considerando que, no Brasil, é maior que na sala de aula visitada.

\section{O futuro do programa IBrasil para esses dois atores}

Ambos consideram que a oportunidade de vivenciar a mobilidade internacional abriu novos caminhos para futuros trabalhos, contatos profissionais com disposição mútua para fazer com que o projeto IBrasil continue produzindo frutos acadêmicos.

\section{Considerações finais}

A pesquisa ora disponibilizada, ao comparar dados relativos ao processo de internacionalização da Educação Superior propiciou a análise de como a área de conhecimento Educação tem trabalhado tal fenômeno, tanto no quesito avaliação pelo Sistema de Avaliação da Pós-Graduação realizada pela Capes, em que os dados apresentados mostram que, dos 471 programas analisados na grande área de Ciências Humanas, 121 são da Educação $(26 \%)$. Analisando, porém, a representatividade desses programas em nota 6 e 7, têm-se, apenas, 9 programas na última trienal (2010-2012), ou seja, 7\% dos 121 programas em Educação, 1,9\% das Ciências Humanas.

Propõe-se a comparação com outras áreas de conhecimento para verificar se a representatividade da inserção internacional foi equivalente em todas as áreas. Percebeu-se, assim, que as Ciências Biológicas apresentaram um total de 23\% de cursos 6 e 7, As Ciências Exatas e da Terra, 20\%, Ciências da Saúde 14\%, com 13\% cada, as Ciências Agrárias e as Engenharias, e as Ciências Humanas $11 \%$.

Dentro da grande área da Ciências Humanas, essa desproporcionalidade entre quantidade de programas existentes e quantidade de programas, 
avaliados em 6 e 7, também foi possível de verificar, sendo que a Educação foi a subárea de conhecimento das Ciências Humanas com menor percentual de programas em 6 ou 7 (7\% de seus programas), comparando aos 19\% de Antropologia/Arqueologia e Ciências Políticas e Relações Internacionais, 18\% da Teologia, 14\% da Filosofia, 12\% de Geografia e Sociologia, 10\% de História e os 9\% da Psicologia.

Os dados apresentados sobre a concessão de bolsas de mobilidade internacional pelo CNPq informam que houve, de fato, um crescimento em investimento de $16,5 \%$, de 2010 a 2014 , o que seria um dado muito positivo, se não fosse comparado ao crescimento de $165,6 \%$ na quantidade de bolsas para o exterior, financiadas para a grande área de Ciências da Saúde.

Contando, também, com o impacto causado nessas bolsas concedidas pelo CNPq, se analisadas aquelas referentes à Graduação Sanduíche pelo Programa Ciência sem Fronteiras (CsF) que, lançado em 2011 , ofereceu 6 bolsas para Ciências Humanas, 48 para Linguística, Letras e Artes, 358 para Ciências Agrárias, 711 para Ciências Biológicas, 999 para Ciências da Saúde, 1038 para Ciências Sociais Aplicadas, 1335 para Ciências Exatas, e da Terra, e 4659 para Engenharias e Ciências da Computação. É válido lembrar que a abertura para a candidatura dessas bolsas para áreas como Ciências Humanas e Linguística, Letras e Artes só ocorreu nas primeiras chamadas / editais do CsF; após essas oportunidades, o CsF fechou para as áreas consideradas não mais como prioritárias, porém contempladas.

Nesse cenário, encontra-se um programa europeu que incentivou a inclusão de cursos tanto das engenharias e tecnologias quanto das licenciaturas em todas as áreas de conhecimento. Isso representou uma oportunidade para que alunos brasileiros de cursos, como o de Pedagogia, pudessem realizar seu estágio em alguma universidade estrangeira.

Tal oportunidade foi analisada por esta pesquisa, colocando, agora em comparação, principalmente, o que a acadêmica em mobilidade para a Espanha e o professor espanhol que veio também pela Educação, com atuação em Educação Superior e Educação a Distância, vivenciaram em suas mobilidades sobre a importância ou necessidade da internacionalização da área de Educação.

Percebe-se que, em seus discursos, a área carece de mais programas que incentivem a internacionalização da Educação, fomentando crescimento 
A internacionalização para as Ciências Humanas no Brasil: um olhar Brasil - Espanha

não somente pessoal para os atores em mobilidade, mas, principalmente, o desenvolvimento da área, a melhoria da qualidade da educação superior, o compartilhamento de conhecimentos visando fomentar o desenvolvimento mundial em base de igualdade de acesso e inserção social.

\section{Nota}

1 Os coautores do artigo são pesquisadores participantes do Projeto Erasmus Mundus IBrasil, de cooperação acadêmica internacional, realizado entre a Université de Lille, a Universidade Estadual Paulista e a Universidade Federal do Rio Grande do Norte, financiado pela Comunidade Europeia (2014-2017). Coordenado na França e no Brasil pelos professores Bertrand Daunay (Laboratoire Théodile CIREL) e Annick Rivens Mompean (Laboratoire SRL) da Université de Lille, e Maria da Conceição Passeggi (Programa de Pós-Graduação em Educação-UFRN).

\section{Referências}

BRASIL. Lei $\mathbf{n}^{\circ}$ 9.394, de 20 de dezembro de 1996. Lei das Diretrizes e Bases da Educação Nacional. Brasília, 1996. Disponível em: http://www.planalto.gov.br/ccivil_03/leis/ 19394.htm. Acesso em: 3 mar. 2014.

Ministério da Educação. Conselho Nacional de Desenvolvimento Científico e Tecnológico. Publicação internacional 2000-2010. Disponível em: www.cnpq.br. Acesso em: 25 ago. 2015.

Ministério da Educação. Conselho Nacional de Desenvolvimento Científico e Tecnológico. Investimento CNPq em bolsas no exterior 2000-2010. Disponível em: www. cnpq.br. Acesso em: 25 ago. 2015.

Ministério da Educação. Conselho Nacional de Desenvolvimento Científico e Tecnológico. Bolsas concedidas em 2014. Disponível em: www.cnpq.br. Acesso em: 25 ago. 2015.

Ministério da Educação. Coordenação de Aperfeiçoamento de Pessoal de Nível Superior. Subárea das Ciências Humanas avaliadas em seus critérios de inserção internacional 2010-2013. Disponível em: www.capes.gov.br. Acesso em: 23 ago. 2015.

Ministério da Educação. Coordenação de Aperfeiçoamento de Pessoal de Nível Superior. Grandes áreas avaliadas em seus critérios de inserção internacional 2010-2013. Disponível em: www.capes.gov.br. Acesso em: 23 ago. 2015. 
Ministério da Educação. Fundação Coordenação de Aperfeiçoamento de Pessoal de Nível Superior. Plano Nacional de Pós-Graduação 2005-2010. Brasília, dez. 2004. Disponível em: http://www.capes.gov.br/capes/. Acesso em: 25 mar. 2013.

Ministério da Educação. Coordenação de Aperfeiçoamento de Pessoal de Nível Superior. Plano Nacional de Pós-Graduação - PNPG 201 1-2020. Brasília: CAPES, 2010. Disponível em http://www.capes.gov.br/images/stories/download/Livros-PNPG-Volume-lMont.pdf. Acesso em: 30 mar. 2013.

Decreto n $^{\circ}$ 7.642, de 13 de dezembro de 2011. Institui o Programa Ciência sem Fronteiras. Disponível em: http://www.planalto.gov.br/CCIVIL_O3/_Ato201 1 $2014 / 2011 /$ Decreto/D7642.htm. Acesso em: 2 mar. 2014.

DE WIT, Harriet. Quality Assurance and Internationalization. Trends, challenges and opportunities INQAAHE conference, Chicago, U.S. 2015. Disponível em http://inqaahe.org/ admin/files/assets/subsites/1/documenten/1429530892_inqaahe-keynote-dewit.pdf. Acesso em: 23 abr. 2016.

FRANÇA, Indira e BONAMINO, Alicia Maria Catalano de. Avaliação e gestão da excelência na Pós-Graduação em Educação. Revista Educação em Questão, Natal, v. 50, n. 36, p. 125-155, set./dez. 2014.

KNIGHT, Jane. Higher Education in Turmoil. The Changing World of Internationalization. Rotterdam (Holanda): Sense Publishers. 2008.

MIURA, Irene Kazumi. O processo de internacionalização da Universidade de São Paulo: um estudo de três áreas do conhecimento. Tese de Livre Docência. São Paulo, Faculdade de Economia, Administração e Contabilidade de Ribeirão Preto, Universidade de São Paulo, 2006.

MOROSINI, Marília Costa. Internacionalização na produção de conhecimento em IES brasileiras: cooperação internacional tradicional e cooperação internacional horizontal. Educação em Revista, Belo Horizonte, v. 27, n. 1, p. 93-1 12, abr. 2011.

SÁ BARRETO, Francisco César. $\bigcirc$ futuro da pós-graduação brasileira. In: STEINER, João Evangelista; MALNIC, Gerhard (Org.). Ensino superior: conceito e dinâmica. São Paulo: Edusp, 2006.

UNESCO. Declaração Mundial sobre Educação Superior no Século XXI: visão e ação - 1998. Disponível em http://www.direitoshumanos.usp.br/index.php/ 
A internacionalização para as Ciências Humanas no Brasil: um olhar Brasil - Espanha

Direito-a-Educa\%C3\%A7\%C3\%A30/declaracao-mundial-sobre-educacao-superior-no-seculo-xxi-visao-e-acao.html. Acesso em: 18 mar. 2013.

Conferência Mundial sobre Ensino Superior 2009: as novas dinâmicas do ensino superior e pesquisas para a mudança e o desenvolvimento social. Paris: Unesco, 2009.

VAN DER WENDE, Marijk. Missing links: the relationship between national policies for internationalization and those for higher education in general and International comparative analysis and syntheses. In: T. älvemark \& M. van der Wende (Eds.). National Policies for the

Internationalization of Higher Education in Europe. Estocolmo: National Agency for Higher Education, 1997.

Prof. Dr. Richard Davis

Université de Lille 3

Vice-presidente de Relações Internacionais

Diretor do Serviço de Relações Internacionais

Diretor da Rede Franco-Holandesa

E-mail: richard.davis@univ-lille3.fr

Prof. Dr. Rafael Sumozas Universidad de Castilla-La Mancha Faculdade de Educação Professor

Diretor do Grupo de Investigação de Ação Educativa

E-mail: rafael.sumozas@uclm.es

Profa. Dra. Flavia Melville Paiva Fundação Universidade Federal de Mato Grosso do Sul Programa de Pós-graduação em Educação

Doutoranda Membro do Grupo de Pesquisa "Políticas Públicas de Educação" UFMS Linha de pesquisa "Estado e Políticas Públicas" UFMS E-mail: flavia.paiva@ufms.br

Recebido 17 jun. 2016 Aceito 21 jul. 2016 